\title{
Risk to life due to flooding in post-Katrina New Orleans
}

\author{
A. Miller ${ }^{1}$, S. N. Jonkman ${ }^{2}$, and M. Van Ledden ${ }^{3}$ \\ ${ }^{1}$ Department of Civil Engineering, Delft University of Technology, Delft, the Netherlands \\ ${ }^{2}$ Delft University of Technology, Delft, the Netherlands \\ ${ }^{3}$ Royal Haskoning DHV, Rdam, the Netherlands
}

Correspondence to: A. Miller (alissa.1.miller@gmail.com)

Received: 30 December 2013 - Published in Nat. Hazards Earth Syst. Sci. Discuss.: 29 January 2014

Revised: 14 November 2014 - Accepted: 11 December 2014 - Published: 12 January 2015

\begin{abstract}
Since the catastrophic flooding of New Orleans due to Hurricane Katrina in 2005, the city's hurricane protection system has been improved to provide protection against a hurricane load with a $1 / 100$ per year exceedance frequency. This paper investigates the risk to life in post-Katrina New Orleans. In a flood risk analysis the probabilities and consequences of various flood scenarios have been analyzed for the central area of the city (the metro bowl) to give a preliminary estimate of the risk to life in the post-Katrina situation. A two-dimensional hydrodynamic model has been used to simulate flood characteristics of various breaches. The model for estimation of fatality rates is based on the loss of life data for Hurricane Katrina. Results indicate that - depending on the flood scenario - the estimated loss of life in case of flooding ranges from about 100 to nearly 500, with the highest life loss due to breaching of the river levees leading to large flood depths. The probability and consequence estimates are combined to determine the individual risk and societal risk for New Orleans. When compared to risks of other large-scale engineering systems (e.g., other flood prone areas, dams and the nuclear sector) and acceptable risk criteria found in literature, the risks for the metro bowl are found to be relatively high. Thus, despite major improvements to the flood protection system, the flood risk to life of post-Katrina New Orleans is still expected to be significant. Indicative effects of reduction strategies on the risk level are discussed as a basis for further evaluation and discussion.
\end{abstract}

\section{Introduction}

Hurricane Katrina struck the southern Gulf Coast of the US on 29 August 2005. The surge caused by the storm overwhelmed the existing flood protection of the city of New Orleans, Louisiana, leading to one of the worst natural disasters in American history. Catastrophic flooding throughout the city led to economic losses of more than 20 billion dollars, and over 1100 people lost their lives in the state of Louisiana, many in the flooded area of New Orleans (Jonkman et al., $2009 b)$. In the wake of the event, the US government committed to provide New Orleans flood protection from a hurricane with a $1 / 100$ per year exceedance frequency, and since then, massive effort, resources and expertise have been employed to do so. However, with any standard there is residual risk and important discussion remains regarding this risk for the upgraded protection system of New Orleans. Moreover, New Orleans' risk of flooding will continue to increase in the future due to many factors, including regrowth of the population and economy as well as physical factors such as sea level rise and ground subsidence (Dixon et al., 2006). This is an issue not only for New Orleans but also for other flood prone areas in the US (Jonkman et al., 2012) and in other parts of the world (Hallegatte et al., 2013).

Risk analysis informs decision making with regard to hazardous events in many contexts, such as the nuclear industry, dam safety and others. Flooding can be considered a large consequence, low probability event, and the same risk approaches can be applied to flood management (Vrijling, 2001). Flood risk management is commonly used in many countries (ICHARM, 2011) and consequences of flooding can include impacts to economy and environment as well as to life and safety and others. Following Kaplan and Gar- 


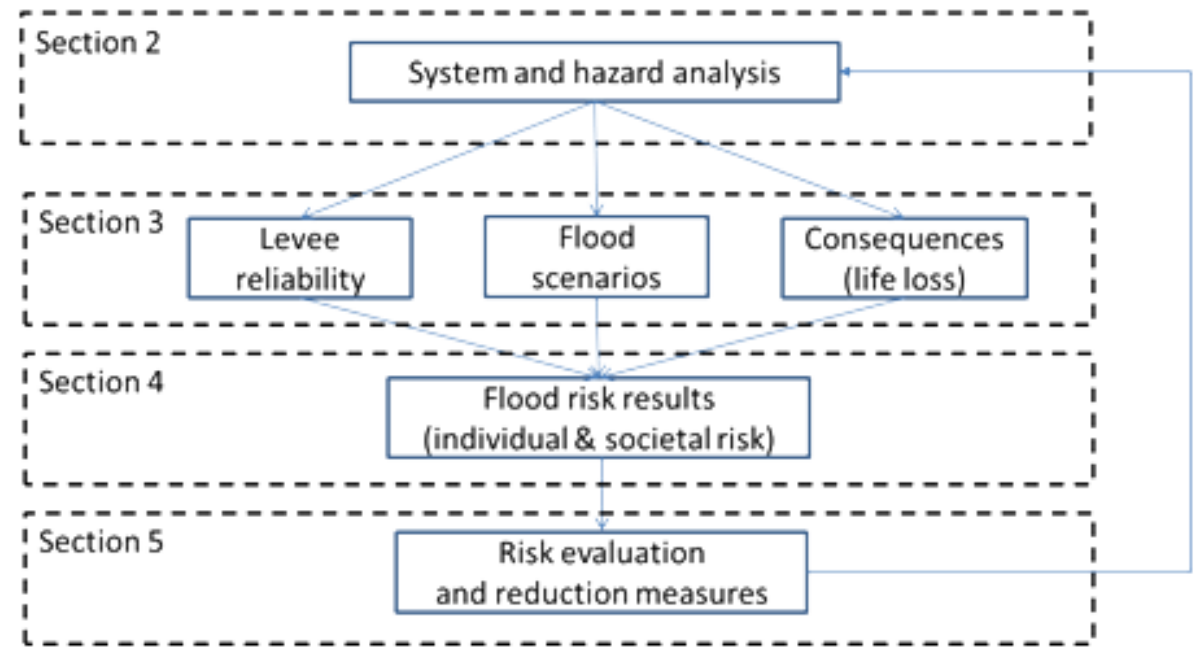

Figure 1. Steps of the flood risk analysis for New Orleans.

rick (1981), risk is defined in this study as a set of scenarios, each of which has a probability and a consequence. Different risk metrics can be used to quantify (different aspects of) risk, i.e., expected damage value to assets and/or environment, and risk to life with metrics such as individual and societal risk (Jonkman et al., 2003). Risk reduction can therefore be accomplished through measures which reduce the probability of flooding, or the consequences of flooding.

The catastrophic loss of life experienced in the wake of Hurricane Katrina and flood events in other parts of the world emphasizes that risk to life is an important aspect of flood risk management strategies. However, the quantification of risk to life not only for New Orleans but also for many other regions is relatively novel in flood risk management for coastal cities, as it is not specified by policy. Many coastal flood risk studies focus on a single aspect of flood risk such as coastal hazard modeling (e.g., Resio and Westerink, 2008) and hazard mapping for risk management and emergency planning (e.g., Bush et al., 1999). Apart from studies in the Netherlands (de Bruijn et al., 2014; Jonkman et al., 2011), risk to life for floods in coastal cities is generally not considered and/or quantified in studies in the US and elsewhere around the world. To gain more insight into risk to life during floods, this study estimates and evaluates the risk to life for New Orleans with the upgraded protection system. The quantified risk can then be evaluated by comparison with tolerable risk and decision criteria applied in other sectors, and potential measures to reduce risk can be explored.

This work also specifically adds to existing flood risk studies for New Orleans (IPET, 2009b; Jonkman et al., 2009a). The Interagency Performance Evaluation Taskforce, or IPET, was established after Hurricane Katrina to conduct an in depth analysis of the city's protection system. The IPET effort included a detailed reliability analysis of the upgraded protection system and results include economic and life loss consequence estimates for various event frequencies. This article supplements the IPET work and differs in various ways. The analyses in the present study are based on twodimensional flood simulations and empirical life loss models based directly on data from Katrina, whereas IPET used other modeling approaches (see IPET, 2007a). Also, the risk to life of the upgraded protection system is evaluated in this study by comparing results to acceptable safety standards found in literature and applied in other engineering sectors. Further, risk reduction measures are analyzed to show the application of risk evaluation in determining the most effective measures. Finally, the combined risk of both hurricane and riverine flooding are considered in this study, whereas IPET only focused on hurricane threat. A riverine flood event, while low probability, is expected to result in disastrous consequences.

To achieve the goal of the study, a risk analysis approach, consisting of system and hazard identification, risk quantification and evaluation of risk, is carried out. The steps of our assessment are summarized in Fig. 1, and the outline of this article follows these steps. The first step in Sect. 2 is the selection of the potential hazards in the New Orleans situation. Next, in Sect. 3, a quantitative risk model for risk to life is presented through the determination of possible flood scenarios and their likelihoods and consequences. In Sect. 4 the results of this model are discussed for both individual and societal risk. Next, Sect. 5 evaluates the quantified risk estimate and compares the results to limits of tolerable or acceptable risk and risks in other sectors. Also, potential measures to mitigate risk are briefly analyzed. Concluding remarks are given in Sect. 6. 


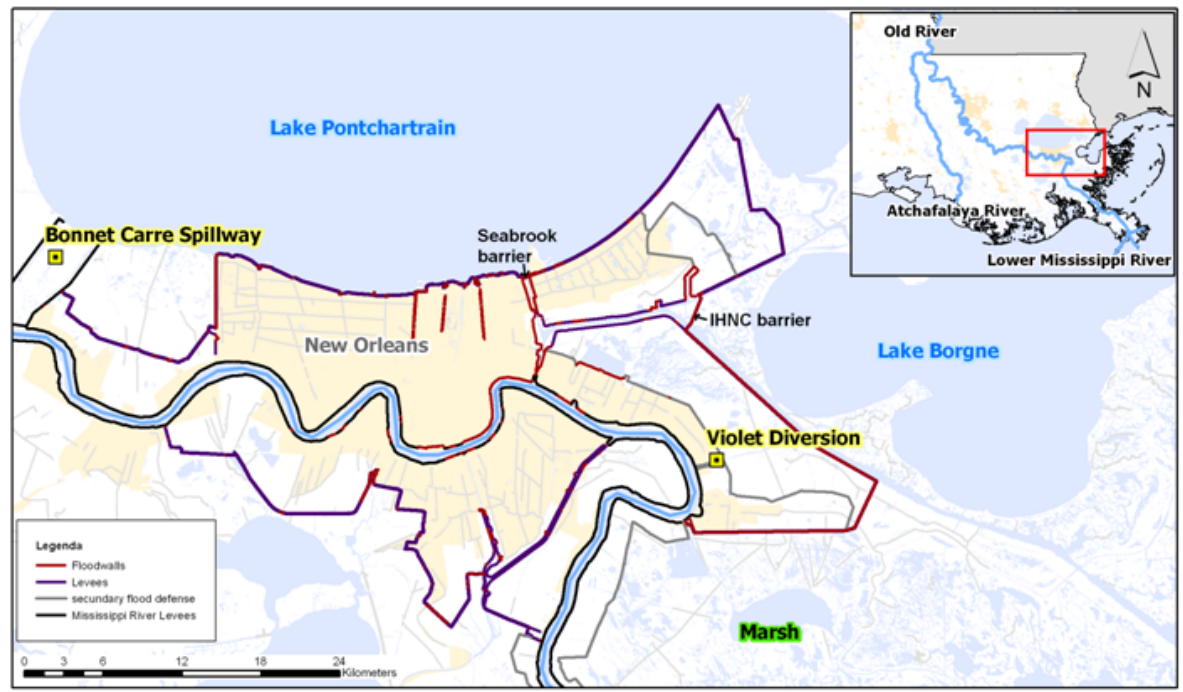

Figure 2. Upgraded flood protection for New Orleans and vicinity.

\section{New Orleans: flood protection system and flood hazards}

\subsection{System description and selection of hazards}

The unique natural environment surrounding New Orleans makes the city highly vulnerable to flooding. Initially built on the high banks of the Mississippi River, New Orleans expanded out into the lower lying marshland over time. This required draining the land to support the growing urbanization, which, combined with the loss of river sediment and other factors, has led to significant ground subsidence over time. Current subsidence rates are estimated at $5-7 \mathrm{~mm}$ per year (Campenella, 2006). Further, the city is bordered by wetlands to the south which serve as a buffer to the coast. The ongoing erosion of these coastal wetlands is increasing the city's proximity to the Gulf of Mexico over time.

Figure 2 depicts the city's surroundings and the system of flood protection. In this study, we consider the post-Katrina flood protection system around the New Orleans metro bowl. The hurricane protection system has been upgraded significantly since 2005. Upgraded protection measures at Lake Pontchartrain include the installation of pumping stations and storm surge barriers where the city's drainage canals meet the lake, effectively shortening the coastline by preventing potential lake surge from filling the canals. To the east of the metro bowl is a man-made shipping canal, the Inner Harbor Navigation Canal (IHNC), which connects to the Mississippi River at the south to the lake at the north and to the confluence of two navigable waterways at the east. Since the storm, two new barriers have been constructed which significantly reduce the opportunity for surge to enter the IHNC. These are the Lake Borgne barrier, constructed east of the IHNC, near the confluence of the two navigable water ways, and the Seabrook barrier, located at the north end of the canal where it meets the lake. Finally, the Mississippi river levee provides protection against river flooding.

As a low-lying area surrounded by water, the city can be flooded by multiple sources: by hurricane surge, a high river flood event and extreme rainfall. In this assessment, flooding due to rainfall is not considered as it is assumed the consequences are less catastrophic. Also, wind-related effects of hurricanes can lead to damages and some fatalities, but are not considered in detail here as it is expected that the number of wind-related fatalities is smaller than flood events. Storms in the past with comparable strength but less flooding caused many fewer fatalities. For example, Hurricane Frederic (1979) occurred in the same area, was of similar strength (category 3) and caused five fatalities. Hurricane Betsy was also of similar strength and led to less extensive flooding than Katrina in mainly the eastern parts of the city, causing $76 \mathrm{fa}-$ talities (FEMA, 2006; 1-28). Since the focus is on flooding due to hurricanes and a river flood event, these aspects are discussed in more detail in Sects. 2.2 and 2.3, respectively.

\subsection{Flooding due to a hurricane surge}

The Gulf of Mexico's warm temperatures during summer months facilitate the occurrence of tropical Storms. The storm's low pressure elevates the sea surface which is then pushed up on the coast by extreme storm winds. Initial inhabitants of the city of New Orleans were protected from coastal flooding by private levees, which were to be replaced by federal protection as authorized by the Federal Flood Control Act of 1946. Before the levees were complete, however, Hurricane Betsy struck the city in 1965 causing catastrophic flooding and significant loss of life. Congress then authorized a system of hurricane protection including levees, flood walls 
and floodgates. Construction for this system began in mid1980s and was expected to be completed in 2015. Before this system could be completed, Hurricane Katrina reached the city in 2005.

After moving over Florida as a hurricane 1 on the SaffirSimpson scale on 25 August, Katrina intensified over the Gulf of Mexico until the central pressure reduced to $902 \mathrm{mb}$ and sustained wind speeds reached $145 \mathrm{mph}$. By 28 August, the storm had become a category 5 hurricane with hurricane force winds that extended 90 nautical miles from the eye of the storm.

The storm made land fall as a category 3 to the east of the city of New Orleans, pushing the surge that had been building up against the east side of the river delta into the city. The surge levels along the eastern side of the city reached 14 to $15 \mathrm{ft}$, i.e., up to $5 \mathrm{~m}$ above the NAVD88 datum level (see IPET, 2007b). Lake Pontchartrain also experienced substantial surge and water level increased up to $10 \mathrm{ft}(3 \mathrm{~m})$ along the southern side of the lake. Further the Mississippi River water level increased significantly during Hurricane Katrina, with the stage reaching $12 \mathrm{ft}(3.24 \mathrm{~m})$ at a location in the city (see Fig. 3).

The massive surge around the city resulted in overtopping and failing levees and flood walls at numerous places. More than 50 breaches were documented in the flood protection of the city system, most due to the overtopping of levees made of hydraulic fill (Sills et al., 2008). However, some flood walls failed prior to being overtopped due to other (geotechnical) failure modes (Seed et al., 2006). For example, sliding due to unstable foundation soils, piping and seepage, and high uplift pressures all caused the failure of flood walls. The consequential flooding left over $80 \%$ of the metropolitan areas under water, an area of roughly $260 \mathrm{~km}^{2}$. Complete dewatering of the city took approximately 6 weeks. It has been estimated that $80 \%$ of the city's residents evacuated prior to the storm (Boyd, 2010) leaving those that remained to shelter in place. After the storm had passed, a massive recovery effort was undertaken to rescue those trapped by the flood. Thousands of people were rescued from roofs, attics, hospitals, nursing homes and other flooded areas by emergency crews. This led to a delay of several days in the evacuation of the city's shelters and conditions in the shelters soon deteriorated due to heat and lack of supplies. Three days after Hurricane Katrina made landfall, buses finally began evacuating people out of the city.

\subsection{Flooding due to a river flood wave}

The contribution of risk of flooding to New Orleans due to a high river event is also considered in this study. The Mississippi River drains the third largest river basin in the world, $3224550 \mathrm{~km}^{2}$ and $40 \%$ of the continental US. Prior to manmade levees, the river's seasonal high flows would overflow the river banks and inundate the floodplain. As the city of New Orleans grew, private levees were built to protect resi-

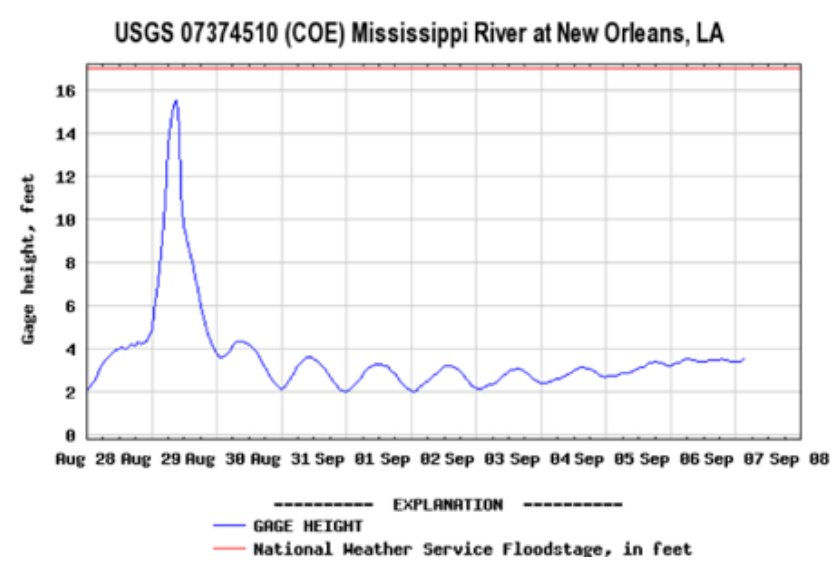

Figure 3. Stage gage reading in the Mississippi River at New Orleans during Hurricane Katrina, demonstrating the increase in stage due to storm surge (Rivergages, 2005).

dents form river floods. But in 1927, a year of heavy rain led to extreme flood flows. $70000 \mathrm{~km}^{2}$ of the Mississippi floodplain were inundated including the alluvial valley. In New Orleans, fear of the city center flooding led city officials to dynamite levees which protected southern, poorer areas of the city. In total, the floodwaters displaced 700000 residents and claimed an estimated 250 lives. The events of 1927 led to the highly controlled and federally mandated Mississippi River levee system, the longest flood protection system in the world. The river level at New Orleans is regulated by a system of upstream spillways. The system was most recently tested in 2011, when record high stages initiated the use of emergency levees and bypass structures to divert flow and control water levels in the lower delta.

\section{Risk to life model approach for New Orleans}

In this section, the model approach and main assumptions for assessing the risk to life during floods in New Orleans is presented.

\subsection{General}

Only a portion of the city of New Orleans is assessed in this article, the area of densest population and greatest economic value. This area, which is referred to as the metro bowl, is roughly $100 \mathrm{~km}^{2}$ (40 square miles) and home to a post-Katrina population in 2010 of roughly 221000 people (US Census Bureau, 2010). Hydraulic boundaries of the studied area consist of Lake Pontchartrain to the north, the Mississippi River to the south, and the IHNC or the Inner Harbor Navigation Canal to the east. The system boundaries of the metro bowl can be seen in Fig. 4. The levees along the Lake Pontchartrain can be directly affected by hurricane induced surge events. The levees along the eastern boundary (IHNC) can be exposed if one of the surge barriers fails. The 


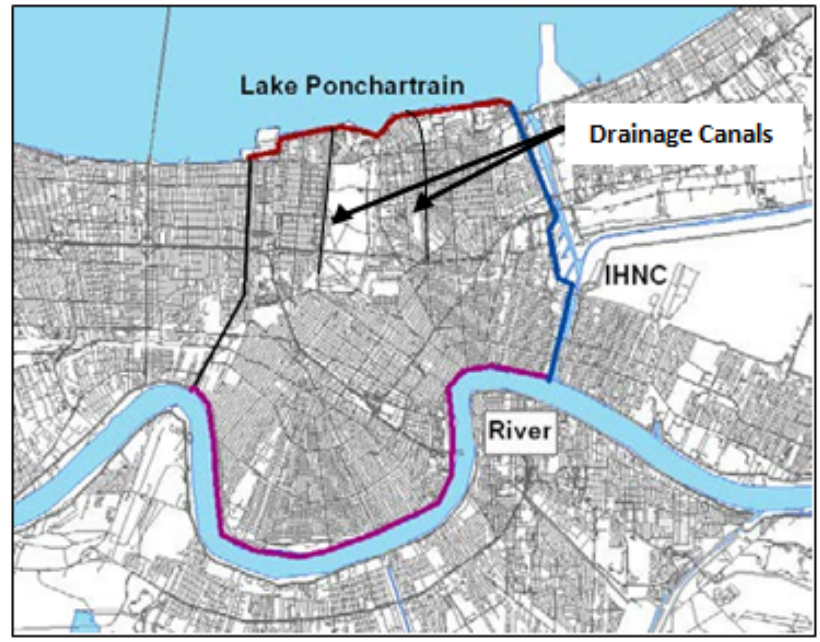

Figure 4. System boundaries for the New Orleans metro bowl.

river levee is affected by both riverine flood events and hurricane induced surges that travel up the river. At this boundary, flooding due to both hydraulic mechanisms is considered. The western boundary of the studied area is a municipal boundary.

\subsection{System reliability}

To determine the reliability of the considered flood protection system of the New Orleans metro bowl, a complete probabilistic analysis should be carried out to consider all possible strength parameters of the system and the possible loads which act on the system. The strength of the system would be characterized by potential failure mechanisms of the protection structures such as overtopping, sliding and piping. Such types of analyses have been made for the New Orleans (IPET, 2009a) and Dutch levee systems (Jongejan et al., 2012). However, since a new system has been designed after Katrina and for simplification in this work, the reliability is based on the system design criteria.

The New Orleans flood protection system after Katrina has been designed to withstand a 1/100 per year hurricane surge according to information from the USACE. Design elevations for the updated hurricane protection have been determined by limiting the allowable overtopping rate for the $1 \%$ hurricane surge and associated waves (see Van Ledden et al., 2008). There is still the potential for failure due to other (geotechnical) failure modes; however, due to robust design specifications, the probability of these failure modes is assumed to be substantially smaller than for an overtopping failure. Therefore, the failure probabilities applied in this study are based on the overtopping failure mode and the corresponding target reliability for the post-Katrina situation. As such, a first approximation for the system failure due to a hurricane load is estimated to be $1 \%$ (but again, more research in the form of full reliability analysis is needed).

Subsequently, it is assumed that the different subsystems and scenarios can be considered independent. This is a conservative assumption, but common for larger flood defense systems with various types of defenses (see e.g., Jongejan et al., 2012). The independence assumption allows each element of the system to be assigned a failure frequency, since for this assumption the scenario probabilities should approximately add up to $1 / 100$ per year.

For example, for the Lake Pontchartrain protection, it is expected the upgraded design can withstand the $1 \%$ event (or 1/100 per year) with some additional margin. Therefore, an estimate for failure probability of the lake protection is determined to be $1 / 150$ per year. Two (independent) breach scenarios along the lake have been considered, each with a probability of $1 / 300$ per year. Along the IHNC, the potential for extreme surge loading has been greatly reduced due to the two new surge barriers. Thus, it was determined the most probable failure would be conditional upon the failure of a gate closure. This combined event of high water and the failure of a gate to close is estimated to have a probability of $1 / 500$ per year. Finally, a scenario with multiple breaches along the lake and IHNC has been assumed with a probability of $1 / 5000$ per year.

The river protection in the region of the delta is designed to consider both riverine and hurricane loading. In the area of the New Orleans metro bowl, levee design is governed by riverine design criteria. Storm surge frequency data (USACE, 2010a) show that the $1 / 1000$ per year water loads due to storm surge traveling up the river are comparable to the current riverine design water levels. Thus, the reliability of the river levee loaded by a hurricane surge traveling up the river a $1 / 1000$ per year.

Finally, for failure of the river levee due to a high river event, the design capacity of the upstream spillways must be exceeded for the water levels at New Orleans to exceed design loading. According to calculations (USACE), the estimated frequency with which river discharge exceeds the upstream spillway capacities is roughly $1 / 880$ per year. This is used as a basis for a river levee reliability estimate of $1 / 1000$ per year.

The relationship between element failures and the undesired consequence can be depicted in a fault tree (see Fig. 5). Assuming independence between the various subsystems and events, the estimated total probability of failure is approximately $1.1 \times 10^{-2}$ per year (1/90 per year). Note that it is also assumed that a failure due to hurricane surges $(1 / 100$ per year) and a failure due to high river discharges $(1 / 1000$ per year) are independent. Correlations and dependencies between the section failure probabilities would be taken into account in a more detailed reliability analysis. 


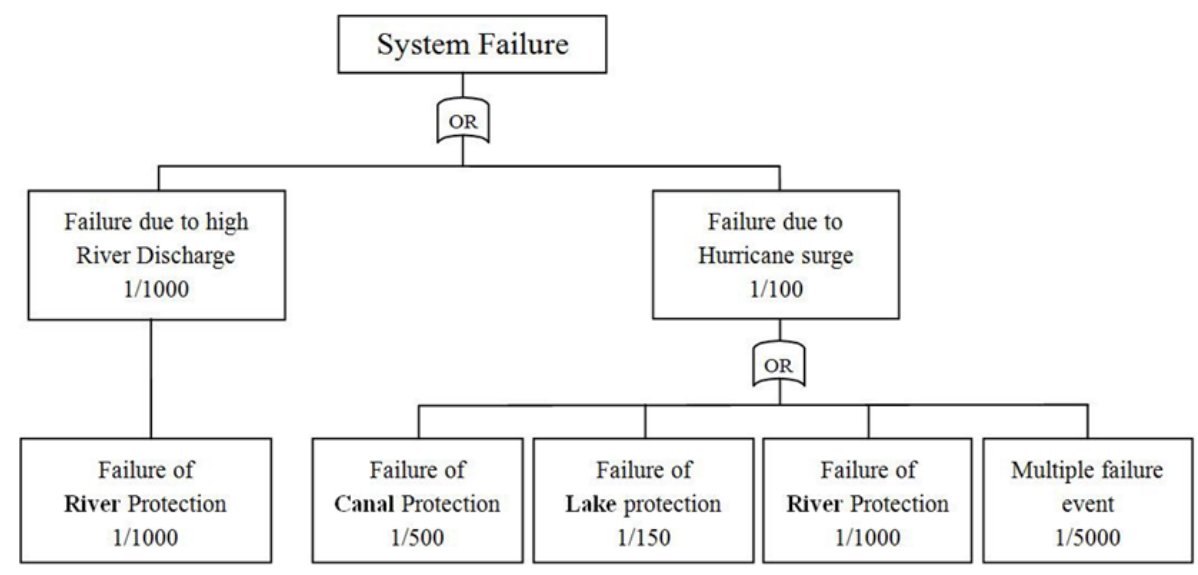

Figure 5. Fault tree depicting the various ways the protection system for the New Orleans metro bowl can fail. The probabilities for the various scenarios are indicated as frequencies per year.

\subsection{Development of flood scenarios}

To estimate the potential consequences of flooding, a limited number of flood scenarios have been defined. Each flood scenario refers to a breach at a certain location in the flood defense system (or a set of multiple breaches) and the resulting pattern of flooding. Scenarios are chosen such that the various potential load mechanisms, the response of the various protection elements, and a range of potential consequences due to flooding are considered. Scenarios with the largest contribution to the overall flooding probability are selected, allowing the most relevant contributions to the overall risk estimate to be included (Jonkman et al., 2008). Thus, more frequent, less damaging events are not simulated.

Characteristics of a scenario include load hydrographs, breach parameters and other factors. For development of the load hydrographs, surge and associated wave characteristics are available for exceedance frequencies up to a $1 / 500$ per year event on the lake and canal, and up to a $1 / 1000$ per year event for surge traveling up the river. This data has been computed using a joint probability model which combines primary hurricane storm parameters to determine frequencies of synthetic hurricane events. For more information on development of hydraulic data, see Resio (2007).

Breaches are modeled to occur when the external load exceeds the design capacity of the defense, and an average hydrograph width is estimated for each scenario based on the synthetic storm hydrograph data. Hurricane breach widths and inverts are based on post-Katrina breach evidence, and riverine breach characteristics are based on literature and documented historical failures. As there is little evidence for breach development time, a simple approach is applied where simulated breaches first grow from the original bank level to ground level in $2 \mathrm{~h}$, and then to a final breach width in three additional hours.
For example, failure of the levees along Lake Pontchartrain is modeled as follows. Two breach locations along the lake are simulated to model a range of flood extents. One breach is located at West End and one breach is located at Bayou St. John (see Fig. 6 for locations). The final breach width is estimated to be $100 \mathrm{~m}$ wide with the breach invert extending to the adjacent ground level. The maximum breach depth is developed 2 hours after the initial breach, and the final width of the breach is reached 5 hours after the initial breach.

A SOBEK 1D2D overland flow model is used to simulate the hydraulic characteristics of each flood scenario. The SOBEK model computes water depth and current velocity as a function of time and space by solving the depth-averaged shallow water equations on a rectangular grid. The model is based on a previously developed model of the New Orleans metro area (see de Bruijn, 2006). The terrain roughness applied in the model is a Nikuradse value of $0.3 \mathrm{~m}$, and sensitivity studies show that model results were minimally sensitive to the roughness value applied. The effects of internal drainage are not included in the model. For the catastrophic effects expected to result due to breaching, it is considered that these effects may only play a minor role in the spreading of the flood waters.

\subsection{Risk to life}

First, loss of life is quantified for every scenario using the hydraulic characteristics (water depth, current velocities) from the flood scenarios. For a given scenario, life loss $(N)$ is quantified with the following formula:

$N=F_{\mathrm{D}}\left(1-F_{\mathrm{E}}\right) N_{\mathrm{PAR}}$,

where $F_{\mathrm{D}}$ is the mortality rate, $F_{\mathrm{E}}$ the evacuation rate and $N_{\text {PAR }}$ the number of people at risk in the flooded area.

The mortality rate $\left(F_{D}\right)$ is the number of deaths due to flooding divided by the population exposed to the flood ef- 

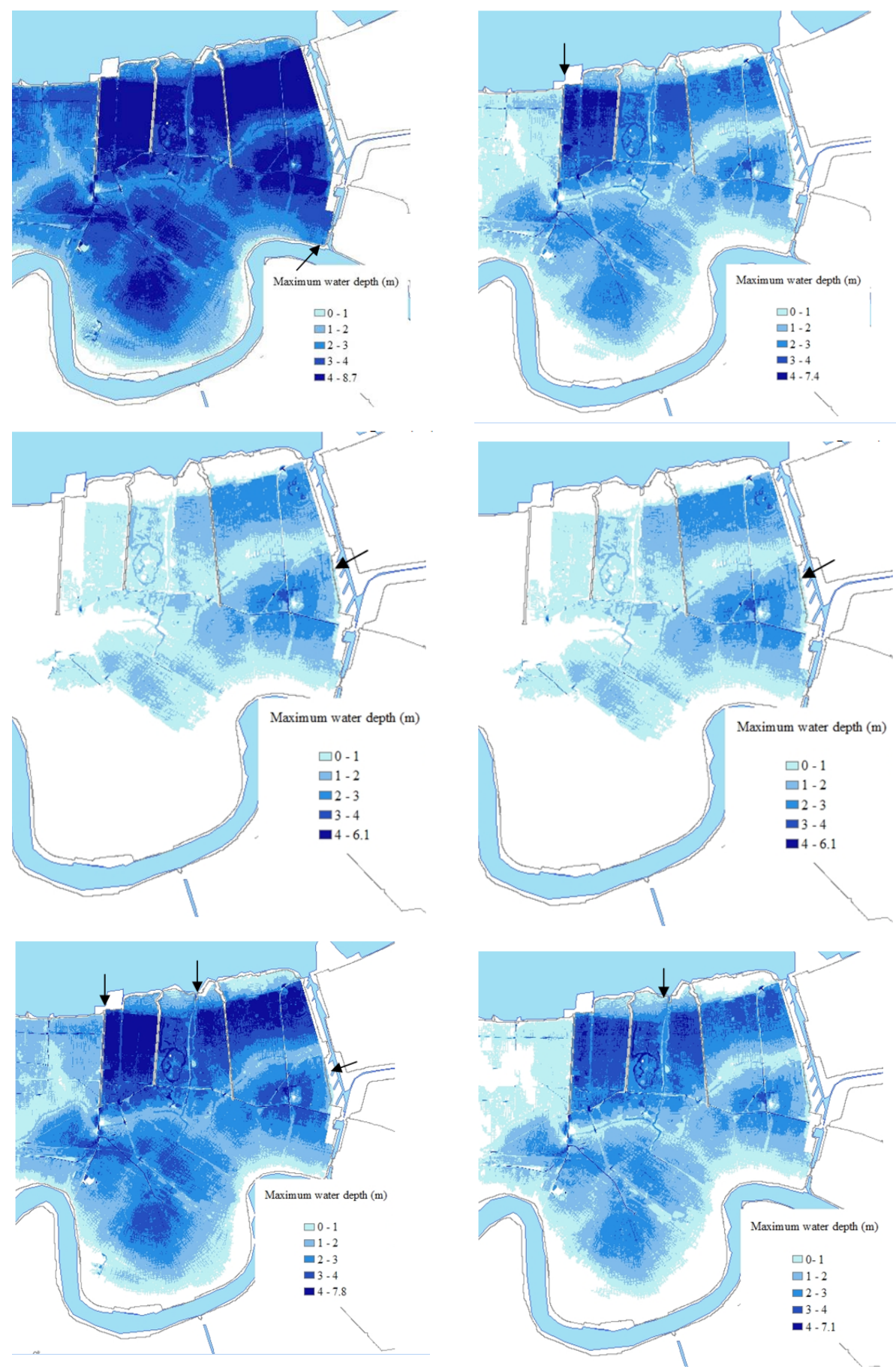

Figure 6. Maximum water depth for the various breach scenarios for the New Orleans metro bowl. Arrows depict breach location.

fects. Local mortality is dependent on local flood conditions and flood severity, and can thus also be represented as a value for a certain location $(x, y)$ and scenario. The mortality functions applied in this study have been derived based on the observations of Hurricane Katrina (Maaskant, 2007; Jonkman et al., 2009b). For the metro bowl, two zones of flood charac- teristics have been distinguished, the breach zone and the remaining zone, which correspond to two mortality functions: 
Table 1. Results: loss of life estimates and assumed failure probabilities for each scenario. For locations of the breaches, reference is made to Fig. 6.

\begin{tabular}{llcccc}
\hline $\begin{array}{l}\text { Flood scenario, } \\
\text { breach location }\end{array}$ & $\begin{array}{l}\text { Failure } \\
\text { probability } \\
(1 / \text { year })\end{array}$ & $\begin{array}{c}\text { Area } \\
\text { flooded } \\
\left(\mathrm{km}^{2}\right)\end{array}$ & $\begin{array}{c}\text { Exposed } \\
\text { population } \\
\text { (with } 90 \% \\
\text { evacuation })\end{array}$ & $\begin{array}{c}\text { Resulting } \\
\text { fatalities }\end{array}$ & $\begin{array}{l}\text { Overall } \\
\text { average } \\
\text { mortality } \\
(\%)\end{array}$ \\
\hline River, high discharge & $1 / 1000$ & 102 & 22000 & 450 & 0.020 \\
River, storm surge & $1 / 1000$ & 91 & 18000 & 150 & 0.008 \\
Lake, West End & $1 / 3000$ & 96 & 17000 & 170 & 0.009 \\
Lake, Bayou St. John & $1 / 300$ & 89 & 20000 & 167 & 0.008 \\
IHNC & $1 / 500$ & 51 & 13000 & 55 & 0.004 \\
Multiple Breach & $1 / 5000$ & 102 & 22000 & 280 & 0.013 \\
\hline
\end{tabular}

Breach zone : $F_{\mathrm{D}}=0.053 h v \geq 5 \mathrm{~m}^{2} \mathrm{~s}^{-1}$,

Remaining zone : $\left.F_{\mathrm{D}}=\Phi_{\mathrm{N}}(\ln (h)-5.20) / 2.00\right)$

$h v<5 \mathrm{~m}^{2} \mathrm{~s}^{-1}$.

In this function $\Phi_{\mathrm{N}}$ denotes the cumulative normal distribution. The breach zone is defined as the area where maximum velocity $\left(v-\left(\mathrm{m} \mathrm{s}^{-1}\right)\right)$ and maximum depth $(h-(\mathrm{m}))$ are greater than $5 \mathrm{~m}^{2} \mathrm{~s}^{-1}$, and all other areas fall into the remaining zone, a function of only maximum depth $(h)$. The hydraulic characteristics maximum depth $(h)$ and maximum velocity $(v)$ follow from the computed flood scenarios with SOBEK 1D2D.

In addition to the mortality rate, the evacuation rate $F_{\mathrm{E}}$ must be assumed for calculating the loss of life. During Katrina, evacuation out of the city was estimated to be about $80 \%$ and about $10 \%$ of the population stayed in shelters such as the Superdome (Jonkman et al., 2009b; Wolshon, 2006). Hurricane Gustav occurred 3 years after Katrina and necessitated large-scale evacuation of New Orleans and adjacent coastal regions. Estimates of evacuation rates for Gustav range from 90 to $97 \%$ (Cutter and Smith, 2009). Despite the higher evacuation rates than during Katrina, Cutter and Smith (2009) mention that "there was some concern that as many as 20,000 of the city's most vulnerable populations did not heed evacuation orders less than 24 hours before the storm's impact." Therefore, in this study a conservative evacuation percentage of $90 \%\left(F_{\mathrm{E}}=0.9\right)$ is applied for hurricane and riverine flood scenarios, which is at the lower end of reported evacuation rates during Hurricane Gustav in 2008.

For determining the number of people at risk $\left(N_{\text {PAR }}\right)$, postKatrina data from the US Census Bureau (2010) is used. The combination of the above information with the outputs of flood simulations results in a life loss estimate for every flood scenario.

Consequently by combination of the above with information on scenario probabilities, the risk to life is quantified by means of both individual risk and societal risk (Jonkman et al., 2003, 2008). While various definitions exist, individual risk can be described as the probability of death of a single person at a given location. The following formula, used to assess individual risk, takes into account the various scenarios that can affect a location and the mortality as a function of flood characteristics. For flood risk, evacuation is generally taken into account, since it is expected to have a significant effect on the risk to people. Therefore, the evacuation fraction $\left(F_{\mathrm{E}}\right)$ is also included in Eq. (3).

$\operatorname{IR}(x, y)=\Sigma P_{i} F_{\mathrm{D} \mid i(x, y)}\left(1-F_{\mathrm{E}}\right)$,

where $\operatorname{IR}(x, y)$ is the individual risk at location $(x, y)\left(\mathrm{yr}^{-1}\right)$, $P_{i}$ is the probability of occurrence of flood scenario $i\left(\mathrm{yr}^{-1}\right)$, $F_{\mathrm{D} \mid i}(x, y)$ is the mortality $F_{\mathrm{D}}$ at location $(x, y)$ given flood scenario $i(-)$ and $F_{\mathrm{E}}$ is the evacuated fraction of the initial population (-).

Another way of quantifying risk to life is the societal risk. This is defined as the probability of exceedance (in a year) of a certain number of fatalities due to one event in a given population or area. This metric, like individual risk, also accounts for evacuation as it is a function of the population directly exposed to the flooding.

\section{Risk to life: results and discussion}

This section presents the results of the risk to life estimates and includes a discussion of the outcomes and main sensitivities in these outcomes.

\subsection{Mortality rate and life loss for the scenarios}

The approach from Sect. 3 has been followed to analyze flood scenarios. Flood depths and extents of the scenarios, including the high river flood scenario can be seen in Fig. 6. Table 1 presents results for the developed flood scenarios. The second column shows the estimated failure probability of the scenario (see above and Fig. 5). The calculated mortality rate for a flood scenario depends on the number of fatalities and the size of the flooded area. Since the number of fatalities is primarily depth dependent, mortality results range from $0.4 \%$ for the breach at the IHNC to $2.0 \%$ for the breach due 


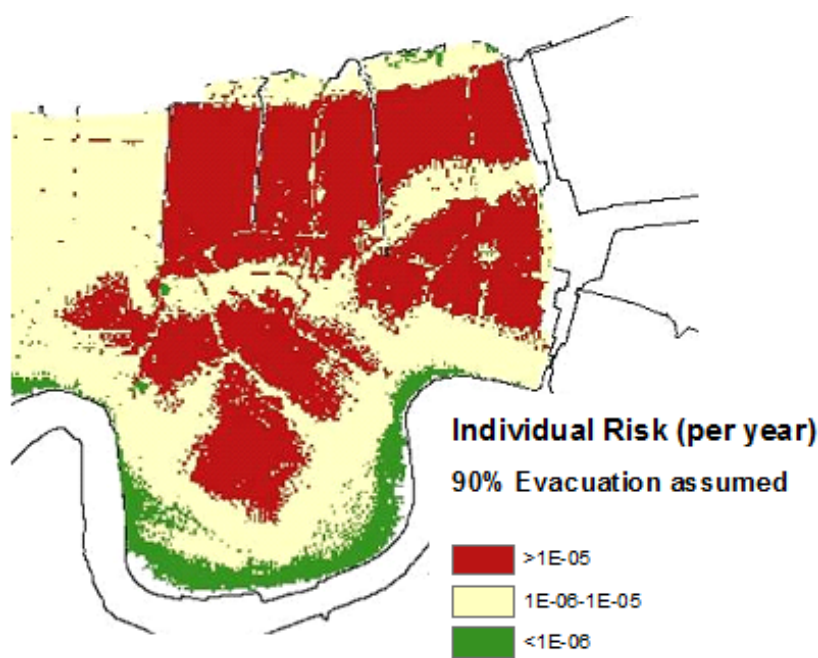

Figure 7. Map of the individual risk for the metro bowl assuming $90 \%$ evacuation. Values are given as probability per year.

to a high river flood event, resulting in fatality estimates in the range of 100-450. Failure of the IHNC is assumed to occur given a gate failure in the storm surge barrier. Therefore, breaching occurs at a more frequent event than for the failures in the rest of the system, and less catastrophic flood effects result. Flooding due to the high river flood event in the river is especially catastrophic as this scenario affects the largest area. Also, flood depths can be large and the duration of the flood wave can be up to several weeks (compared to hurricane duration of several hours). After levee breaching due to the high river event, the metro bowl is expected to continue to fill, resulting in flood depths of over $5 \mathrm{~m}$ in some areas. Lessons learned from Katrina and other floods shows that closure of breaches during inflow is generally not possible.

As the results are the function of assumptions used in models with various uncertainties, they give an indication of the order of magnitude of potential life loss. Sensitivity of the results to several variables is investigated (see also Miller, 2011 for further details). It was found that results are not sensitive to final breach dimensions as ultimate flood extents and depths will eventually match the boundary water level (de Bruijn, 2006). The load hydrograph duration for hurricane events did impact results as increased load duration leads to an increase in maximum water depths. The effect of hydrograph duration on the risk could be evaluated in further analysis. Overall, however, flood extents, characteristics and resulting mortality rates of the hurricane flood scenarios are comparable to events that occurred during Hurricane Katrina. It is estimated that roughly 250 persons perished in the metro bowl due to direct flood effects during Katrina and an area with about 250000 inhabitants was flooded (Jonkman et al., 2009b). While significant improvements have been made to the protection system, resulting in reduced failure probabili-

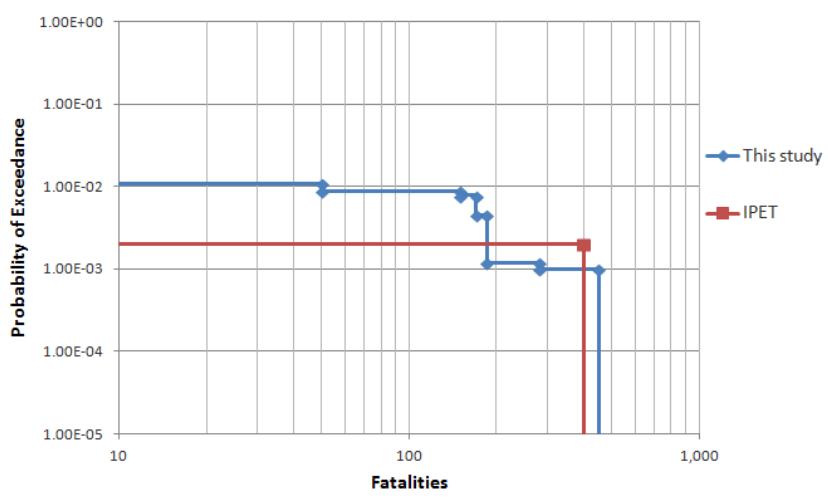

Figure 8. Results of this study (risk estimate for the metro bowl) and results of IPET (2009b) for post-Katrina situation and with $0 \%$ pumping assumed for the $1 / 500$ per year estimate and $100 \%$ pumping assumed for the $1 / 50$ and $1 / 100$ per year estimate.

ties, occurrence of any of the flood scenarios is still expected to result in catastrophic flooding of the metro bowl due to the low-lying geography of the area.

\subsection{Risk to life}

Figure 7 shows the results of individual risk (IR) for the metro bowl. The metro bowl largely has an IR value greater than $10^{-5}$ per year (i.e., $1 / 100000$ per year) with a maximum value of $5 \times 10^{-5}$ per year. As the IR is a function of a depth-dependent mortality function, the risk largely corresponds with the area topography. Figure 8 presents the societal risk for the metro bowl. This so-called FN curve (frequency number) plots the probability (per year) that $n$ fatalities are exceeded. The intersection with the $y$ axis is the cumulative probability of the scenarios in Table 1 . The studied area's overall flooding probability is $1.1 \times 10^{-2} \mathrm{yr}^{-1}$ (i.e., $1 / 90$ per year). The intersection with the $x$ axis is the consequence result of the scenario with the largest consequences, roughly 450 fatalities. Probability and fatality estimates for the scenarios are combined to determine the annual expected number of fatalities, about 2 fatalities/year.

An important assumption for the calculation of the risk to life is the evacuation fraction. This number has been set to a realistic but somewhat conservative estimate of $90 \%$ in our calculations. This implies that $10 \%$ of the initial population is assumed to be the exposed population and loss of life estimates are reported for these values. Changing the evacuation percentage to $95 \%$ would halve the exposed population and thus life loss. Reported results are thus somewhat conservative. Especially since warning and prediction processes are different for a riverine event, the evacuation rate assumption should be investigated for this event further in a more detailed analysis. Also, as part of future work, the uncertainty in evacuation success could be assessed by means of a probabilistic analysis, in which conditional probabilities are assigned to various evacuation scenarios (Kolen et al., 2013). 
The societal risk curve is constructed using the results of the IPET (2009b) study and plotted in comparison to the results of this study (Fig. 10). The IPET curve is constructed for the loss of life estimates for the metro bowl for events with probabilities of $1 / 50,1 / 100$ and $1 / 500$ per year according to the IPET study estimates. In this comparison, the IPET results plotted for the 1/50 and 1/100 per year events assume $100 \%$ pumping capacity as in the IPET approach; rainfall flooding is the main risk contributor for these events. This results in no loss of life plotted for these events. However, the 1/500 per year IPET estimate plotted assumes no pumping, as no significant pumping is expected when levees breach. IPET results include rainfall flooding, but do not consider riverine flooding (IPET, 2009b). IPET uses a pre-Katrina exposed population and an $80 \%$ evacuation rate (IPET, 2007a), a higher initial population and smaller evacuation rate than assumed in this study and may explain the higher loss of life result of the low probability event. Despite variations in assumptions, however, it can be seen the societal risk results are in the same range.

\section{Risk evaluation and risk reduction}

\subsection{Individual risk criterion}

The results presented in the previous section are indicative but also preliminary estimates of the risk to life of the New Orleans metro bowl in the post-Katrina situation. The estimated risk is evaluated by comparison with criteria for acceptable risk found in literature and risks for other systems. Two main sources of evaluation criteria include a framework developed by Vrijling et al. (1995), and proposed safety reference guidelines for dams and levees of the USACE (USACE, 2010b). Acceptable individual risk considers the viewpoint of the individual, who weighs the risks against benefits before undertaking an activity (Vrijling et al., 1995). Proposed criteria for this risk by Vrijling et al. (1995), is based upon the argument that tolerable individual risk for non-voluntary activities be 1 or 2 orders of magnitude lower than the average fatality rate for youth. This rate is roughly $10^{-4}$ per year in the western world (Vrijling et al., 1995). Thus, the following equation for individual risk describes a tolerable risk level:

$\mathrm{IR}<\beta \times 10^{-4}$,

where $\beta$ is referred to as the policy factor and represents the level of voluntariness of the activity (greater voluntariness corresponds to a higher $\beta$ value). A value of $\beta=0.1$ is considered for flood protection in the Netherlands, where flood protection in urban areas is considered a relatively involuntary situation. This results in a proposed tolerable risk level of $10^{-5}$ per year in the Netherlands. The application of this framework to less voluntary applications, for example

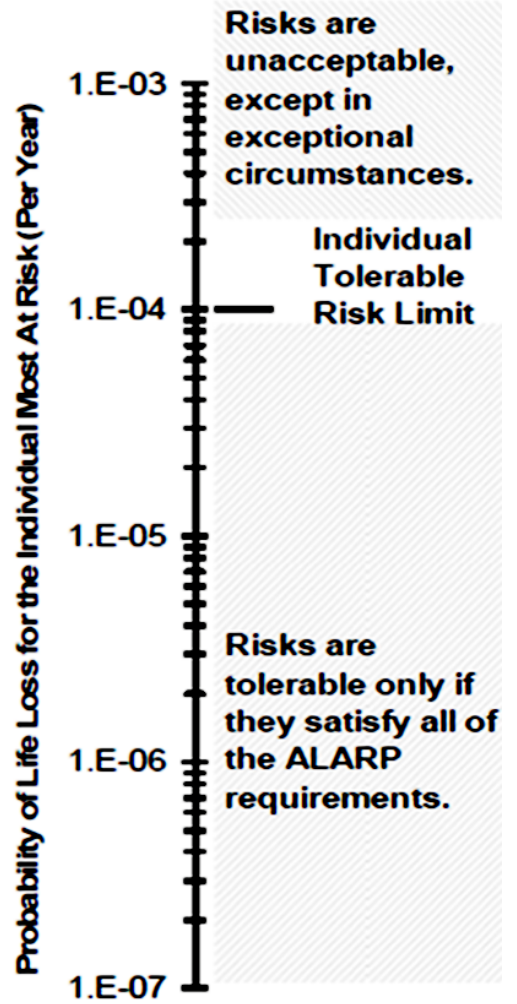

Figure 9. Proposed individual risk thresholds according to the updated USACE guidelines for levee safety (USACE, 2010b).

in industrial safety, applies a more conservative beta value of 0.01 , resulting in a lower tolerable risk of $10^{-6}$.

Individual risk criteria proposed by recent USACE guidelines are based on existing tolerable risk levels in dam safety and other fields such as land use planning. It was agreed on by the Corps that a tolerable risk level of $10^{-4}$ had achieved consensus among government and private sectors institutions engaged in safety management (USACE, 2010b). While $10^{-4}$ per year is less risk averse than that proposed by Vrijling (2001), an additional consideration discussed in the USACE guidelines is the use of a buffer zone to characterize between tolerable and acceptable risk criterion. This buffer zone falls between $10^{-6}$ and $10^{-4}$, and is known as the ALARP (as low as reasonably practical) zone. The range provides for the many complex factors involved in determining acceptable risk such as cost effectiveness and societal concern (see Fig. 9). When assessing the individual risk for New Orleans, the risk is relatively low in comparison with the probability of a car accident for example $\left(10^{-4}\right.$ per year), and falling within the tolerable risk range of the USACE (between tolerable and acceptable risk). However, the majority of the metro bowl results in IR values higher than $10^{-5}$ per year, exceeding the acceptable level of individual risk proposed by Vrijling (2001) and currently used for evaluating flood risks in the Netherlands (Jonkman et al., 2011). 


\subsection{Societal risk criterion}

Individual risk reflects the individual perspective. In addition, society as a whole is averse to large, multi fatality events. Such events provoke a greater social political response such that societal risk criteria is generally more conservative than individual (Baecher, 2009). To evaluate societal risk, the FN curve is plotted against an acceptable limit line. One proposed limit line representing the threshold for socially acceptable risk in the Netherlands is the following:

$1-F(N)<C_{N} / N^{\alpha}$,

where $F(N)$ is the cumulative distribution function of the number of fatalities, $C_{N}$ is a constant that determines the vertical position of the limit line $\left(\mathrm{yr}^{-1} \mathrm{fat}^{-\alpha}\right), \alpha$ is the risk aversion coefficient and slope of the limit line; the height of the limit line $\left(C_{N}\right)$ and the value of risk aversion coefficient are subject to academic and societal discussion. In previous studies values of $C_{N}=11$ and $\alpha=2$ have been proposed for flood management in the Netherlands (Jonkman et al., 2008; Vrijling et al., 1998).

The tolerable societal risk level recently proposed by the USACE in the context of levee safety is also investigated. This limit line is largely based on the US Bureau of Reclamation's dam safety program (USBRC, 2003) which uses a base rate of $10^{-4}$ per year for a loss of life of 10 . The slope or risk aversion coefficient $\alpha$ of 1 is applied here, placing equal weight on exceedance probabilities and numbers of fatalities. This reflects a more risk neutral approach than the Dutch approach which uses a slope of $\alpha=2$ to reflect risk aversion.

Finally, probability consequences data produced for common risks in the field of civil infrastructure (Lambe et al., 1982) is compared to the results of this study in Fig. 10. It is noted that some of the displayed risks in Fig. 10 have substantially reduced since the time of the publication (e.g., air traffic). This data results in a limit line delineating a historically acceptable risk level at which various structures perform (Whitman, 1981). This line has a a base rate of $10^{-2}$ per year for a loss of life of 10 , with a slope of roughly $\alpha=1$.

This comparison allows insight into the relative magnitude of risk of different domains to be related to the magnitude of risk to life of the city of New Orleans. Note that this study considered only the metro bowl, and not all Katrina-related fatalities occurred in this area. If the risks for the current situation are assessed taking into account other areas (parts of New Orleans and Louisiana) that would be affected by hurricane induced flooding, the loss of life and risk estimates for the current situation would be higher.

Figure 11 plots the results of this study with the discussed tolerable risk limit lines for societal risk. It is seen that the societal risk for New Orleans exceeds the explored tolerable risk lines most notably when compared against the updated USACE tolerable risk guidelines for dams. As dam safety is considered an involuntary activity with little direct benefit to those affected by the risk (Vrijling et al., 1995), the

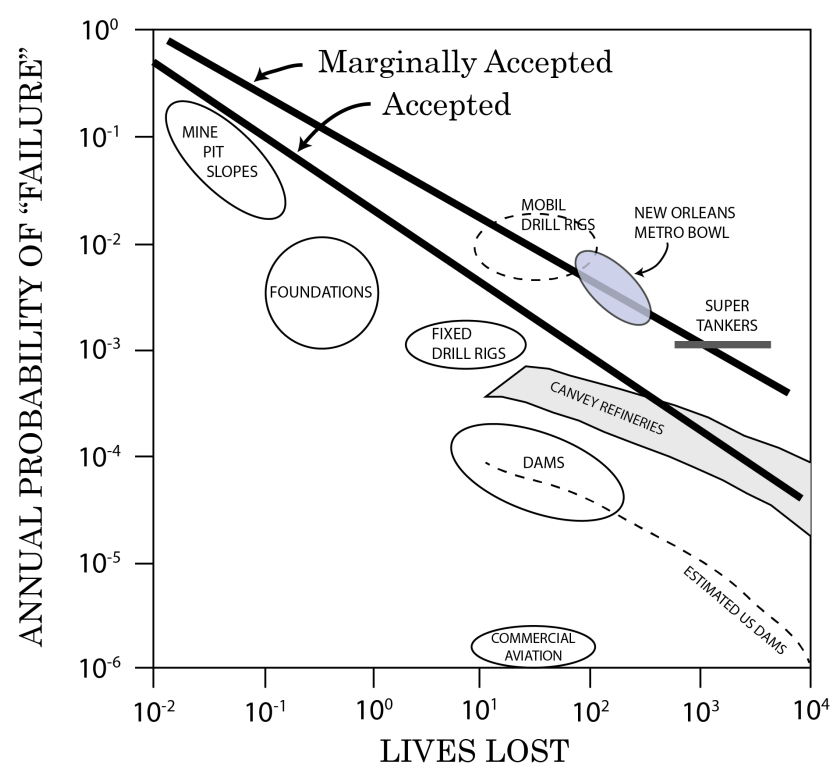

Figure 10. FN chart of common civil infrastructure risks (Lambe et al., 1982).

USACE limit criterion is conservative. However, even comparison with less conservative tolerable risk levels shows that the actual risk is higher than acceptable levels. A further discussion of the accepted failure probabilities according to the various perspectives is included in the next section.

\subsection{Effectiveness of measures to reduce risk}

Overall, the risk assessment aims to support rational decision making regarding risk-bearing activities (Apostolakis, 2004). Outcomes of risk assessment can be used in the design process to decide on the required safety levels of new systems (e.g., a new tunnel) or to support decisions on the acceptability of safety levels and the need for measures in existing systems (e.g., a flood defense system). A quantitative measure of some form is needed to transfer decisions on acceptable safety into a technical domain (Voortman, 2004). Examples are choices in the design of civil structures such as the height of a flood defense or the strength of a building. The results of this study can also be used to analyze the effects of various risk reduction strategies in a systematic way. Risk reduction measures can be categorized into measures that reduce event probability and that reduce event consequences.

Measures that reduce the event probability include strengthening and upgrading of the levees as well as measures that reduce the hydraulic load on the system, such as barrier islands and wetland restoration. The protection level required for the New Orleans metro bowl in order to comply with tolerable risk criteria is listed in Table 2. This required protection level has been determined as follows. For the individual risk perspective, the protection level has been changed so that the IR for the locations with the highest risk falls be- 


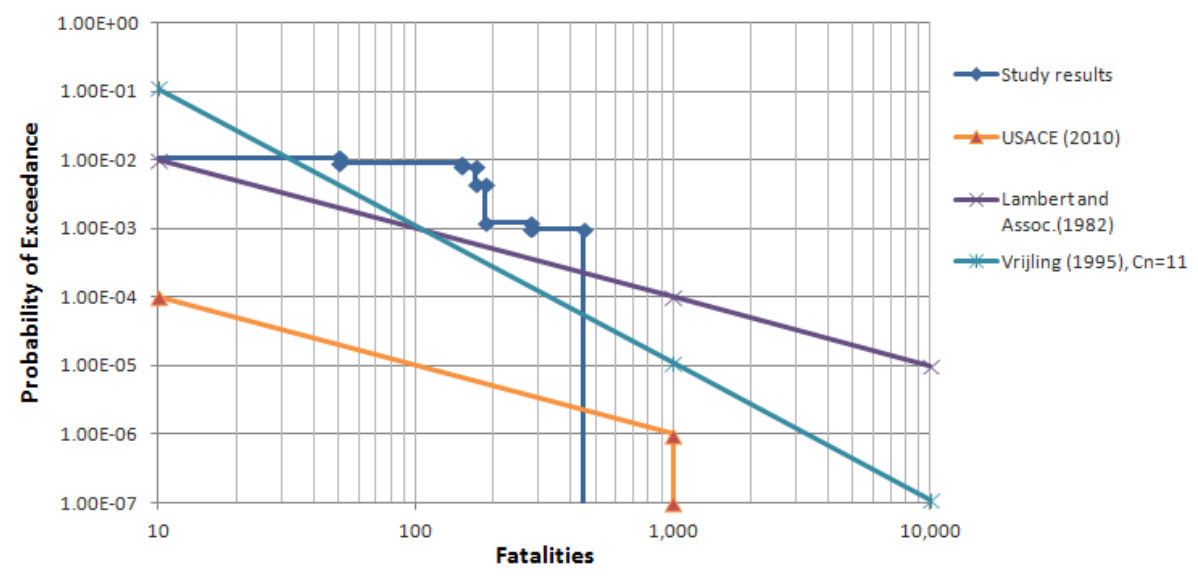

Figure 11. Societal risk estimate for the New Orleans metro bowl compared to limits proposed in literature.

low the threshold. For the societal risk criteria, the failure probability has been reduced so that the FN curve falls below the limit line. The required protection levels in Table 2 show that most of the criteria for individual and societal risk would lead to protection levels of $1 / 10000$ per year or higher. It is interesting to note that the $1 / 10000$ per year protection level is also adopted in the Netherlands for some of the flood prone areas with the highest values and population densities.

The risk reducing effect of various measures is difficult to quantify, but the developed risk framework can be used as basis. A detailed assessment of the effects of measures is outside the direct scope of this paper, but to demonstrate the application and considerations a preliminary analysis of the risk reduction of some measures is presented as a basis for further discussion and elaboration. Strategies for which risk reduction effects have been discussed include: increased protection, elevation of homes, improved evacuation and relocation of population to higher areas.

The cost effectiveness of the risk reducing measures related to life loss reduction can be evaluated by quantifying the Cost, eXtra Statistical (CSX) value, or the cost of saving an extra statistical life (see e.g., Tengs et al., 1995). This index is a ratio of the cost of each proposed measure divided by the risk reduction provided by the measure:

$\mathrm{CSX}=I / \Delta E(N)$,

where CSX is the cost of saving an extra statistical life per year (USD/fat/year), $I$ is investment (USD) and $\Delta E(N)$ is the change (reduction) in expected number of fatalities (fat/year). Note the lower the ratio between the investment and the saved lives, the more cost effective the measure (i.e., lower CSX).

Table 3 summarizes the indicative costs, remaining risks and CSX value for different risk reduction measures using Eq. (6). These results show that increasing evacuation is the most cost effective as it limits the exposed population at a relatively low cost. A $1 / 500$ per year protection level is the next
Table 2. Metro bowl protection levels required to meet each proposed risk criterion.

\begin{tabular}{ll}
\hline Criterion & $\begin{array}{l}\text { Probability } \\
(1 / \text { year })\end{array}$ \\
\hline Individual risk $<10^{-5} \mathrm{yr}^{-1}$ & $1 / 4000$ \\
Individual risk $<10^{-6} \mathrm{yr}^{-1}$ & $1 / 10000$ \\
\hline Vrijling (2001) (national) & $1 / 25000$ \\
FN criterion, USACE & $<1 / 1000000$ \\
FN 1982 Plot & $1 / 10000$ \\
\hline Economic optimization* & $1 / 1000-1 / 4000$ \\
\hline$*$ Economic optimization based on Jonkman et al. (2009a).
\end{tabular}

most cost effective followed by the elevation of homes. Finally, the reductive effect of relocating the population within the metro bowl is minimal due to the large flood extents of the scenarios. It is noted that some measures, such as increased evacuation, are effective to reduce the risk to life, but would not limit other types of risk, such as the economic risk that would result from widespread flooding. Further elaboration of the risk framework and measures is needed to come to a realistic assessment of risk reduction effectiveness. Such an analysis should also include an economic appraisal of costs and benefits of several risk reduction strategies.

\section{Concluding remarks}

An analysis of the risk to life for the city of New Orleans has been carried out. The quantification of risk to life is not required by current policy in most countries and is relatively novel in flood risk management. Results show that the risk to life, while considerably reduced from the pre-Katrina status (see also IPET, 2009b), is still significant. The quantified individual risk to life exceeds the criterion proposed by Vrijling et al. (1995) and falls within the range of tolerability 
Table 3. Preliminary cost estimates and resulting CSX values for risk reduction measures. Results are for illustration purposes, further investigation of measures, associated costs and risk reduction is recommended.

\begin{tabular}{|c|c|c|c|c|c|c|}
\hline Measure & Description & $\begin{array}{r}\text { Cost, } \\
\text { USD } 10^{6}\end{array}$ & Source & $\begin{array}{l}\text { Resulting } E(n) \\
\text { (fat./year) }\end{array}$ & $\begin{array}{l}\% E(n) \\
\text { reduced }\end{array}$ & $\begin{array}{l}\text { CSX value } \\
\text { (USD/fat/yr) }\end{array}$ \\
\hline Elevate homes & $\begin{array}{l}5 \mathrm{ft}(1.52 \mathrm{~m}) \text { water depth } \\
\text { reduction }\end{array}$ & 4000 & Estimate & 0.5 & $73 \%$ & $2.7 \times 10^{9}$ \\
\hline Increased protection & $\begin{array}{l}1 / 500 \text { year level of protection } \\
\text { (hurricane protection only) }\end{array}$ & 2000 & Bos (2008) & 0.75 & $62 \%$ & $1.5 \times 10^{9}$ \\
\hline Evacuation & $95 \%$ of population evacuated & 34 & USACE (2010c) & 1 & $50 \%$ & $2 \times 10^{7}$ \\
\hline $\begin{array}{l}\text { Relocated population } \\
\text { relocated (roughly } \\
50000 \text { persons) }\end{array}$ & Persons in high risk zone & 2000 & Hoss (2010) & 1.5 & $26 \%$ & $4 \times 10^{9}$ \\
\hline
\end{tabular}

criteria defined by the USACE (2010b). The quantified societal risk exceeds proposed criteria found in literature and is higher than acceptable societal risk quantified in other sectors. Thus, while there is not a consensus on an acceptable risk to life criteria, the post-Katrina risk to life for New Orleans is relatively high. Investigation into the quantified effects of risk reduction strategies shows that evacuation can be effective to reduce life loss, but hardly affects economic risk. Evacuation and various other measures can be considered as part of a risk management strategy for New Orleans (see also Lopez, 2009). Based on the results of this study, and the anticipated future increase in flood risk, further discussion regarding the management and reduction of flood risk for New Orleans is recommended. Application of risk standards and acceptable risk criteria at a national and local level are anticipated to be an important aspect in the future of flood risk management. Finally, the results of this study can be used for risk communication to affect risk awareness.

The results presented have been based on only a limited number of flood scenarios. For a more complete evaluation, it is recommended to include a more complete set of flood scenarios to better represent possible load situations, breach combinations and flood conditions. Reliability estimates are first order and preliminary and expected to be conservative. A more complete reliability analysis should be carried out to verify and improve these estimates. As the approach has considered solely a portion of the city, application to the remaining metropolitan areas of New Orleans provides a better overall picture of the risk. Reduction measures that reduce the hydraulic load can be analyzed in greater detail and quantified. A more comprehensive risk analysis can be carried out to include economic risk considerations.

Disclaimer. This work was carried out as part of research at TU Delft and this article does not necessarily reflect the views of USACE or other organizations.

Edited by: H. Kreibich

Reviewed by: G. Le Cozannet and another anonymous referee

\section{References}

Apostolakis, G. E.: How useful is quantitative risk assessment?, Risk Analysis, 24, 515-520, 2004.

Baecher, G.: Quantifying flood Risk, ASFPM Foundation Symposium, http://www.asfpmfoundation.org/forum/Quantifying Flood_Risk_FINAL.pdf (last access: November 2013), 2009.

Bos, A.: Optimal safety levels for the New Orleans East polder, traineeship report, Royal Haskoning, New Orleans, 2008.

Boyd, E. C.: Estimating and Mapping the Direct Flood Fatality Rate for Flooding in Greater New Orleans due To Hurricane Katrina, Risk Hazards Crisis Publ. Policy, 1, 91-114, 2010.

Bush, D. M., Neal, W. J., Young, R. S., and Pilkey, O. H.: Utilization of geoindicators for rapid assessment of coastal-hazard risk and mitigation, Ocean Coast. Manage., 42, 647-670, 1999.

Campanella, R.: Geographies of New Orleans, Urban Fabrics Before the Storm. Center for Louisiana Studies, University of Louisiana, Lafayette, 63 pp., 2006.

Cutter, S. L. and Smith, M. M.: Fleeing from the Hurricane's Wrath: Evacuation and the Two Americas, Environment MarchApril 2009, http://www.environmentmagazine.org/archives/ back_issues/march-april_2009/cutter-smith-full.html (last access: July 2014), 2009.

de Bruijn, K. M.: Improvement of casualty functions based on data of the flooding of New Orleans, in: 2005 WL Delft Hydraulics Report Q3668.00, Deltares Research Report, 2006.

de Bruijn, K. M., Diermanse, F. L. M., and Beckers, J. V. L.: An advanced method for flood risk analysis in river deltas, applied to societal flood fatality risk in the Netherlands, Nat. Hazards Earth Syst. Sci., 14, 2767-2781, doi:10.5194/nhess-14-27672014, 2014.

Dixon, T. H., Amelung, F., Ferretti, A., Novali, F., Rocca, F., Dokka, R., Sella, G., Kim, S. W., Wdowinski, S., and Whitman, D.: Subsidence and flooding in New Orleans, Nature, 441, 587-588, doi:10.1038/441587a, 2006.

FEMA - Federal Emergency Management Agency: Hurricane Katrina in the Gulf Coast, Mitigation assessment team report, Building performance observations, recommendations and technical guidance, FEMA Report 549, http://www.fema.gov/es/ media-library/assets/documents/406 (last access: January 2015), 2006. 
Hallegatte, S., Green, C., Nicholls, R. J., and Corfee-Morlot, J.: Future flood losses in major coastal cities, Nat. Clim. Change, 3, 802-806, 2013.

Hoss, F.: A comprehensive assessment of Multilayered Safety in flood risk management, Msc Thesis, Delft University of Technology, Delft, the Netherlands, 2010.

ICHARM: Large scale flood report, http://www.ifihome.info/ icfmicharm/Large_Scale_Flood_ReportWeb.pdf (last access: June 2014), 2011.

IPET - Interagency Performance Evaluation Task Force: Performance evaluation of the New Orleans and southeast Louisiana hurricane protection system, Volume VII: The consequences, Final Report, 26 March 2007a.

IPET: Performance evaluation of the New Orleans and southeast Louisiana hurricane protection system, Volume IV: The storm, Final Report, 26 March 2007b.

IPET: Performance evaluation of the New Orleans and Southeast Louisiana Hurricane Protection System, Volume VII: Engineering and Operational Risk and Reliability Analysis, Final report, June 2009a.

IPET: A General Description of Vulnerability to Flooding and Risk for New Orleans and Vicinity: Past, Present and Future, in: Supplemental Report of the Interagency Performance Evaluation Task Force, edited by: Link, L. E., 2009b.

Jongejan, R., Stefess, H., Roode, N., Ter Horst, W., and Maaskant, B.: The VNK2-project: a fully probabilistic risk analysis for all major levee systems in the Netherlands, in: Floods: From Risk to Opportunity, IAHS Red Book, IAHS Press, Oxfordshire, 75-85, 2012.

Jonkman, S. N., van Gelder, P. H. A. J. M., and Vrijling, J. K.: An overview of quantitative risk measures for loss of life and economic damage, J. Hazard. Mater., A99, 1-30, 2003.

Jonkman, S. N., Vrijling, J. K., and Kok, M.: Flood risk assessment in the Netherlands: A case study for dike ring South Holland, Risk Analysis, 28, 1357-1373, 2008.

Jonkman, S. N., Kok, M., van Ledden, M., and Vrijling, J. K.: Riskbased design of flood defence systems: a preliminary analysis of the optimal protection level for the New Orleans metropolitan area, J. Flood Risk Manage., 2, 170-181, 2009a.

Jonkman, S. N., Maaskant, B., Boyd, E., and Levitan, M. L.: Loss of Life Caused by the Flooding of New Orleans After Hurricane Katrina: Analysis of the Relationship Between Flood Characteristics and Mortality, Risk Analysis, 29, 676-698, doi:10.1111/j.1539-6924.2008.01190.x, 2009b.

Jonkman, S. N., Jongejan, R. B., and Maaskant, B.: The Use of Individual and Societal Risk Criteria within the Dutch Flood Safety Policy - Nationwide Estimates of Societal Risk and Policy Applications, Risk Analysis, 31, 282-300, 2011.

Jonkman, S. N., Hiel, L. A., Bea, R. G., Foster, H., Tsioulou, A., Arroyo, P., Stallard, T., and Harris, L.: Integrated Risk Assessment for the Natomas Basin (CA) Analysis of Loss of Life and Emergency Management for Floods, ASCE Nat. Hazards Rev., 13, 297-309, 2012.

Kaplan, S. and Garrick, B. J.: On The Quantitative Definition of Risk, Risk Analysis, 1, 11-27, 1981.

Kolen, B., Kok, M., Helsloot, I., and Maaskant, B.: EvacuAid: A Probabilistic Model to Determine the Expected Loss of Life for Different Mass Evacuation Strategies During Flood Threats, Risk Analysis, 33, 1312-1333, 2013.
Lambe, T. W. and Associates: "Acceptable risk at Kawasaki site 400", Report prepared for Towa Nenryo Kogyo co. Ltd. (now, TONEN Corporation), Kawasaki, Japan, edited by: Beacher, G. B., and Marr, W. A., Cambridge, MA, 1982.

Lopez, J. A.: The Multiple Lines of Defense Strategy to Sustain Coastal Louisiana, J. Coast. Res., 54, 186-197, 2009.

Maaskant, B.: Research on the relationships between flood characteristics and fatalities, Based on the flooding in New Orleans caused by Hurricane Katrina, Msc thesis, Delft University of Technology, Delft, the Netherlands, 2007.

Miller, A.: Risk to life due to flooding in post-Katrina New Orleans, Msc thesis, Delft University of Technology, Delft, the Netherlands, 2011.

Resio, D. T.: White Paper, Estimating Hurricane Inundation Probabilities, US Army Corps of Engineers, ERDC-CHL, USACE, Vicksburg, MS, USA, 2007.

Resio, D. T. and Westerink, J.: Modeling the physics of storm surges, Phys. Today, 61, 33-38, 2008.

Rivergages.com.: August 2005, USGS, 2010.

Seed, R. B., Bea, R. G., Abdelmalak, R. I., Athanasopoulos, A. G., Boutwell, G. P., Bray, J. D., Briaud, J.-L., Cheung, C., CobosRoa, D., Cohen-Waeber, J., Collins, B. D., Ehrensing, L., Farber, D., Hanemann, M., Harder, L. F., Inkabi, K. S., Kammerer, A. M., Karadeniz, D., Kayen, R. E., Moss, R. E. S., Nicks, J., Nimmala, S., Pestana, J. M., Porter, J., Rhee, K., Riemer, M. F., Roberts, K., Rogers, J. D., Storesund, R., Govindasamy, A. V., Vera-Grunauer, X., Wartman, J. E., Watkins, C. M., Wenk Jr., E., and Yim, S. C.: Investigation of the performance of the New Orleans flood protection systems in Hurricane Katrina on August 29, 2005, Independent Levee Investigation Team, Final Report, http://www.ce.berkeley.edu/projects/neworleans/ (last access: June 2014), 2006.

Sills, G. L., Vroman, N. D., Wahl, R. E., and Schwanz, N. T.: Overview of New Orleans Levee Failures: Lessons Learned and Their Impact on National Levee Design and Assessment, J. Geotech. Geoenviron. Eng., 134, 556-565, 2008.

Tengs, T. O., Adams, M. E., Pliskin, J. S., Gelb Safran, D., Siegel, J. E., Weinstein, M. C., and Graham, J. D.: Five-hundred live saving interventions and their cost effectiveness, Risk Analysis, 15, 369-390, 1995.

USACE: HSSDRS Guidelines, Elevations for design of hurricane protection levees and structures, New Orleans, http://www.mvn.usace.army.mil/Missions/Engineering/ HurricaneDesignGuidelines/HurricaneDesignGuidelines.aspx (last access: January 2015), 2010a.

USACE: Levee safety program and tolerable risk guidelines, http: //www.nfrmp.us/docs/10-R-8.pdf (last access: December 2014), 2010b.

USACE: New Orleans Shelter Support Study, New Orleans Emergency Planning, prepared by PBS \& J, 2010c.

USBRC: United States Department of the Interior, Bureau of Reclamation, Guidelines For Achieving Public Protection In Dam Safety Decision-making, 15 June 2003, Denver, 2003.

US Census Bureau: 2010 Census of Population and Housing, US Census Bureau, Washington, D.C., 2010.

Van Ledden, M., Lynett, P., Resio, D. T., and Powell, N. J.: Probabilistic design method of levee and floodwall heights for the hurricane protection system in the New Orleans Area, Proceedings of the 10th International Workshop on Wave Hindcasting 
and Forecasting and Coastal Hazard Symposium 11-16 November 2007, Hawaii, 2008.

Voortman, H. G.: Risk-based design of large-scale flood defence systems, PhD thesis, Delft University, Delft, the Netherlands, 2004.

Vrijling, J. K.: Probabilistic design of water defence systems in the Netherlands, Reliab. Eng. Syst. Safety, 74, 337-344, 2001.

Vrijling, J. K., van Hengel, W., and Houben, R. J.: A framework for risk evaluation, J. Hazard. Mater., 43, 245-261, 1995.
Vrijling, J. K., van Hengel, W., and Houben, R. J.: Acceptable risk as a basis for design, Reliab. Eng. Syst. Safety, 59, 141-150, 1998.

Whitman, R.: Seventeenth Terzaghi lecture, ASCE Convention and Exposition, ASCE, Reston, VA, 1981.

Wolshon, B.: Evacuation planning and engineering for Hurricane Katrina, Roads Bridges, 36, 27-34, 2006. 